\title{
Percutaneous transforaminal endoscopic discectomy in a nine-year-old patient with sciatica: case report, technical note and overview of the literature
}

\author{
P. S. Gadjradj ${ }^{1}$ (D) B. S. Harhangi ${ }^{2}$ \\ Received: 23 February 2021 / Accepted: 17 March 2021 / Published online: 27 March 2021 \\ (C) The Author(s) 2021
}

\begin{abstract}
Percutaneous transforaminal endoscopic discectomy (PTED) is an alternative procedure to open microdiscectomy (OM) to treat sciatica caused by lumbar disk herniation. Even though robust evidence comparing PTED with OM is lacking, PTED is becoming increasingly popular to treat spinal disorders. In this technical report, the surgical technique and outcomes of PTED in a 9-year-old patient are described. Furthermore, an overview of the literature on full-endoscopic techniques to treat sciatica is given, showing that PTED is feasible, safe and effective to treat lumbar disk herniation in the pediatric population.
\end{abstract}

Keywords Endoscopic discectomy · Lumbar disk herniation · Pediatrics

\section{Introduction}

In contrary to the adult population in which sciatica caused by lumbar disk herniation is frequently observed, pediatric lumbar disk herniation is a rare entity $[1,2]$. Whereas lumbar disk herniation among adults is a result of degeneration of the spine with dehydrated disks, lumbar disk herniations in the pediatric population are typically a result of hydrated disks and are more associated with trauma [3]. Even though sciatica in the pediatric population responds worse to conservative treatment than in the adult population, conservative management remains the first-line treatment of sciatica as it is less invasive for the developing spine [4, 5].

However, when conservative treatment fails, surgery should be considered [6]. Throughout the years, attempts were made to reduce the surgical invasiveness of conventional microdiscectomy by developing other "minimally invasive" techniques [7]. One of these techniques is percutaneous

P. S. Gadjradj

p.gadjradj@erasmusmc.nl

1 Department of Neurosurgery, Park MC, Hoofdweg 90, Rotterdam, The Netherlands

2 Department of Neurosurgery, Erasmus MC University Medical Center Rotterdam, Rotterdam, The Netherlands transforaminal endoscopic discectomy (PTED), which is usually associated with less surgical trauma as no paraspinal muscles are detached from their insertion and the bony integrity is largely preserved [8]. There is, however, a paucity in research on the surgical treatment of sciatica in the pediatric population and more specifically in the minimally invasive management.

Therefore, the current study was aimed to describe the PTED-technique with its technical nuances to treat pediatric lumbar disk herniation, and to give an overview of the literature on the use of full-endoscopic techniques to treat lumbar disk herniation in patients aged 18 years or lower.

\section{Case presentation}

A 9-year-old female patient had been suffering from sciatica in her left leg for 6 months. Aside from the disabling pain in her left leg, she suffered from dysesthesia. Upon neurological examination, she had a mild paresis distal in her left leg and a positive straight leg raise test at 30 degrees. Apart from her father undergoing lumbar discectomy at 11 years old and her parental grandfather having rheumatoid arthritis, no other diseases have been reported in the family. Magnetic resonance imaging revealed a paramedian disk herniation at L5-S1 on the left side (Fig. 1a, b). She was firstly managed conservatively with physical therapy and pain relieving medications. Because of progressive symptoms, she received an epidural 
Fig. 1 Magnetic resonance imaging showing a median/ paramedian lumbar disk herniation at L5-S1 on the left site in sagittal (a) and axial plane (b). c, $\mathbf{d}$ the sagittal and axial MRI, respectively, six months after surgery. No residual disk herniation is visible and the nerve root at L5-S1 at the left site is adequately decompressed
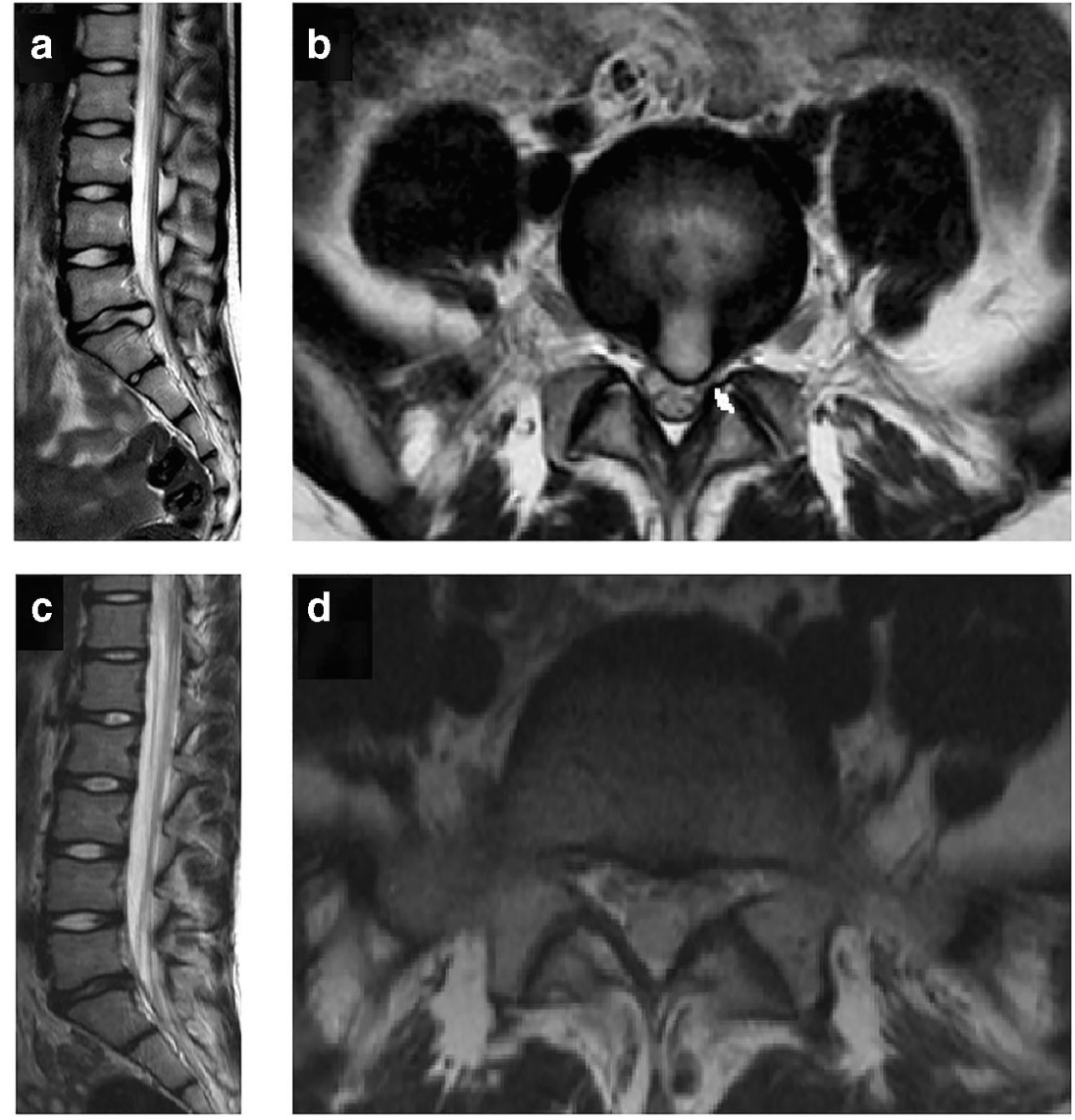

steroid injection which did not show sufficient efficacy. Eventually, she also developed a contracture in her left foot and was referred to the neurosurgery department. Because of the preferences of her parents, she was referred to a neurosurgeon with expertise in endoscopic spine surgery. Preoperative clinical outcomes are shown in Table 1.

\section{Surgical technique}

The PTED-technique as performed for adults has been extensively described previously [8]. Local anesthesia with lidocaine and intravenous analgesia and sedation are used utilizing a combination of dexmedetomidine and remifentanil. The goal is to have the patient under conscious sedation to enable intraoperative feedback of the patient.

The patient was positioned prone on a Wilson frame with the patient's arms positioned cranially. After disinfection, a sterile screen-drape was applied. Biplane fluoroscopy was used for radiography. The skin entry point was indicated $8-$ $9 \mathrm{~cm}$ from the midline superior to the iliac crest with an oblique angle to the L5-S1 disk level (Fig. 2a) which is shorter in comparison to adults which is $12-14 \mathrm{~cm}$ from the midline. After injecting the skin entry point with $3 \mathrm{~mL}$ of $1 \%$ lidocaine, an $18 \mathrm{G}$ needle was introduced with its tip located at the superior articular process (SAP) of $\mathrm{S} 1$. There, $2 \mathrm{~mL}$ of $1 \%$ lidocaine was injected, and then, the needle was advanced through the lateral part of the SAP into the spinal canal. Then, a guidewire was inserted through the spinal needle (Fig. 2b). At this stage, an 8-mm skin incision was made, and a standard endoscopic transforaminal procedure was performed with widening of the foramen. Then, an 8-mm working cannula was inserted into the disk space, crossing the medial pedicular line into the disk herniation in the spinal canal (Fig. 2c). The endoscope was introduced through the cannula, and a continuous irrigation system was used to ensure clear endoscopic view, identifying the SAP, posterior longitudinal ligaments, disk herniation, and the spinal canal (Fig. 2d). Decompression was performed with different types of forceps via the working channel of the endoscope until free pulsation of the $\mathrm{S} 1$ nerve was identified. After decompression, a single subcutaneous suture and a sterile strip were applied on skin incision. Total duration of surgery was 48 minutes and blood loss was less than $50 \mathrm{~mL}$.

\section{Discussion}

This case report and technical note describe the PTEDtechnique as performed for a nine-year-old patient. 
Table 1 Clinical outcomes at baseline, short-term and long-term follow-up

\begin{tabular}{|c|c|c|c|c|}
\hline & Baseline & 2 hours postoperative & 6 months follow-up & 12 months follow-up \\
\hline VAS leg pain $(0-10)^{\dagger}$ & 8 & 0 & 0 & 0 \\
\hline VAS back pain $(0-10)^{\dagger}$ & 5 & 0 & 0 & 0 \\
\hline Functional status $(1-5)^{*}$ & 4 & - & 1 & 1 \\
\hline Quality of life $(1-5)^{*}$ & 4 & - & 1 & 1 \\
\hline Days per month not able to do daily activities & $>21$ & - & 0 & 0 \\
\hline Self-perceived recovery of symptoms $s^{\ddagger}$ & - & - & Fully recovered & Fully recovered \\
\hline Self-perceived recovery of leg pain & - & - & Fully recovered & Fully recovered \\
\hline Satisfied with change & - & - & Fully satisfied & Fully satisfied \\
\hline Anxiety for local anesthesia $(0-10)^{\complement}$ & 7 & - & - & - \\
\hline Satisfaction with local anesthesia $(0-10)^{\complement}$ & - & 9 & - & - \\
\hline
\end{tabular}

$\dagger$ The visual analogue scale for leg pain and back pain measures pain from a 0 to 10 scale with " 0 " indicating no pain and " 10 " maximal pain

*The questions regarding functional status and quality of life measures these two outcomes on a five-point scale with "1" indicating an excellent functional status/quality of live and " 5 " the worst functional status/quality of life

* Self-perceived recovery and satisfaction was measured using a 7-point Likert scale with fully recovered/satisfied and almost fully recovered/satisfied dichotomized as fully recovered/satisfied

' Anxiety and satisfaction with local anesthesia was measured with a 0 to 10 VAS with " 0 " indicating no anxiety/fully unsatisfied and " 10 " maximal anxiety/ fully satisfied

Postoperatively, she experienced no further back or leg pains. These outcomes remained so until the last follow-up time one year after surgery (Table 1). No complications occurred. Even though our patient was anxious about the procedure before surgery, her postoperative experience was satisfactory.

The results of the literature review are shown in Table 2. Five studies reporting the outcomes of full-endoscopic surgery in lumbar disk herniation in children could be identified [9-13]. A total of 110 patients were described undergoing percutaneous endoscopic discectomy either under general or local anesthesia. According to the modified McNab score, $93.6 \%$ of the patients (103 out of 110) had an excellent or good outcome after surgery. Furthermore, the complication rates were low and reported only transient sensor or motor symptoms. Two patients developed recurrent disk herniation which required re-discectomy during follow-up.

Some limitations of the PTED-technique have to be acknowledged. One issue may be the reimbursement of the technique which can oppose a financial barrier to providing PTED. These reimbursement issues may also be caused by the lack of high-level evidence on the merits of PTED over conventional microdiscectomy $[14,15]$. Aside from these reimbursement and scientific issues, local anesthesia may also not be suited for all children. Finally, as intraoperative fluoroscopy is extensively used during surgery, children are also exposed to radiation.

In conclusion, PTED is a safe and effective treatment option for pediatric lumbar disk herniation. However, PTED
Fig. 2 Preoperative images with (a) the skin entry point shown at $8-9 \mathrm{~cm}$ off the midline, (b) the insertion of the guidewire into the neural foramen, (c) insertion of the cannula, and (d) the view through the endoscope showing the nerve root
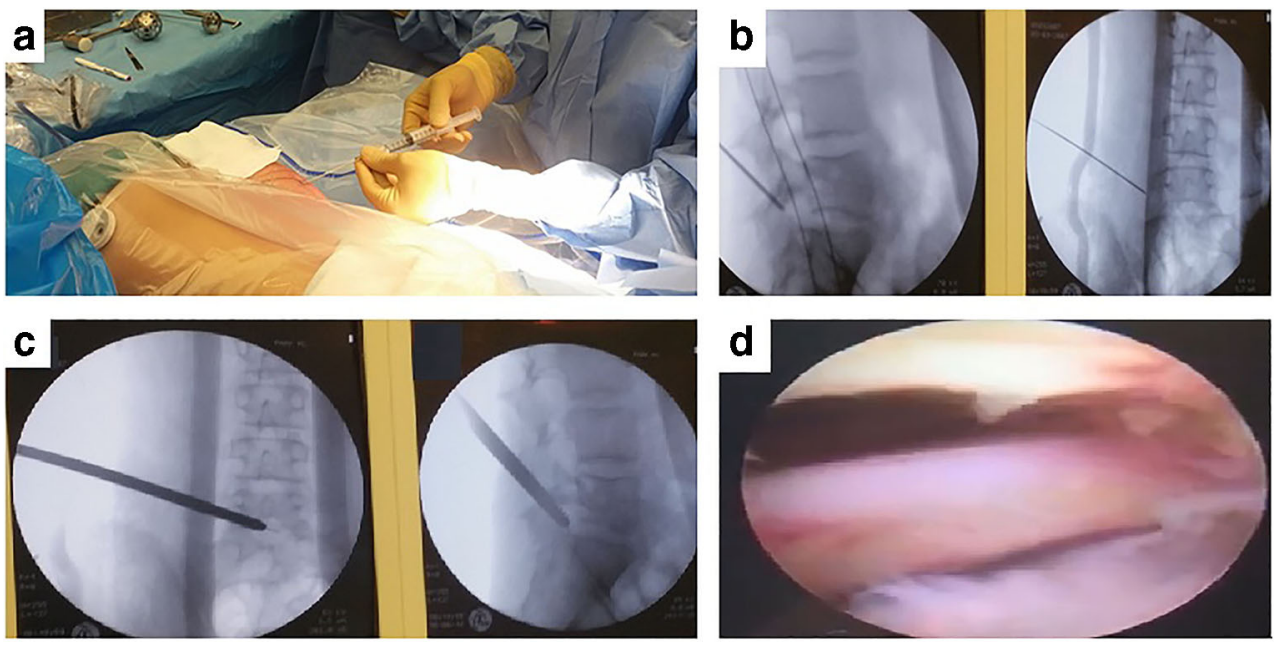
Table 2 Overview of the literature on full-endoscopic procedures to treat sciatica caused by lumbar disk herniation in the pediatric population (age $\leq 18$ years)

\begin{tabular}{|c|c|c|c|c|c|c|c|c|}
\hline Author and year & $\begin{array}{l}\text { Sample } \\
\text { size }\end{array}$ & $\begin{array}{l}\text { Age } \\
\text { (years) }\end{array}$ & Technique & Anesthesia & Level & Clinical outcomes & $\begin{array}{l}\text { Complications/ } \\
\text { recurrence }\end{array}$ & Follow-up \\
\hline Chen et al. 2018 [9] & 19 & $13-18$ & $\begin{array}{l}\text { Transforaminal } \\
\text { Interlaminar }\end{array}$ & Local & L4-5, L5-S1 & $\begin{array}{l}\text { McNab: excellent }(52.6 \%), \\
\text { good }(47.4 \%)\end{array}$ & $1 \times$ recurrence & 41.7 months \\
\hline $\begin{array}{l}\text { Lee et al. } 2006 \\
\quad[10]\end{array}$ & 46 & $13-18$ & PELD & & $\begin{array}{l}\text { L3-4, L4-5, } \\
\quad \text { L5-S1 }\end{array}$ & $\begin{array}{l}\text { McNab: excellent or good } \\
(91.3 \%) \text {. }\end{array}$ & $\begin{array}{l}1 \times \text { transient } \\
\text { dysesthesia } \\
1 \times \text { recurrence }\end{array}$ & 37.2 months \\
\hline $\begin{array}{l}\text { Mayer et al. } 1996 \\
\text { [11] }\end{array}$ & 4 & $8-17$ & Transforaminal & Local & L4-5, L5-S1 & $\begin{array}{l}\text { McNab: excellent }(75 \%) \\
\text { good }(25 \%)\end{array}$ & None & $1-5$ years \\
\hline $\begin{array}{l}\text { Wang et al. } 2014 \\
\text { [12] }\end{array}$ & 29 & $13-18$ & Interlaminar & General & L4-5, L5-S1 & $\begin{array}{l}\text { McNab: excellent (83\%), } \\
\text { good (10\%), and fair (7\%) }\end{array}$ & $\begin{array}{l}1 \times \text { transient } \\
\text { pareses }\end{array}$ & 19.7 months \\
\hline $\begin{array}{l}\text { Zheng et al. } 2016 \\
\text { [13] }\end{array}$ & 12 & $11-16$ & Transforaminal & Local & $\begin{array}{l}\text { L3-4, L4-5, } \\
\quad \text { L5-S1 }\end{array}$ & $\begin{array}{l}\text { McNab: excellent }(50 \%) \text {, good } \\
(41.7 \%) \text { and fair }(8.3 \%)\end{array}$ & $\begin{array}{l}1 \times \text { transient } \\
\text { paresthesia }\end{array}$ & $\geq 12$ months \\
\hline
\end{tabular}

may not be feasible among all pediatric patients as it is usually performed under conscious sedation.

Abbreviations OM, open microdiscectomy; PTED, percutaneous transforaminal endoscopic discectomy; RCT, randomized controlled trial; VAS, visual analogue scale; SAP, superior articular process

\section{Declarations}

Conflict of interest Both authors have no conflict of interest to disclose.

Open Access This article is licensed under a Creative Commons Attribution 4.0 International License, which permits use, sharing, adaptation, distribution and reproduction in any medium or format, as long as you give appropriate credit to the original author(s) and the source, provide a link to the Creative Commons licence, and indicate if changes were made. The images or other third party material in this article are included in the article's Creative Commons licence, unless indicated otherwise in a credit line to the material. If material is not included in the article's Creative Commons licence and your intended use is not permitted by statutory regulation or exceeds the permitted use, you will need to obtain permission directly from the copyright holder. To view a copy of this licence, visit http://creativecommons.org/licenses/by/4.0/.

\section{References}

1. Konstantinou K, Dunn KM (2008) Sciatica: review of epidemiological studies and prevalence estimates. Spine (Phila Pa 1976) 33: 2464-2472

2. Bruske-Hohlfeld I, Merritt JL, Onofrio BM, Stonnington HH, Offord KP, Bergstralh EJ, Beard CM, Melton LJ 3rd, Kurland LT (1990) Incidence of lumbar disc surgery. A population-based study in Olmsted County, Minnesota, 1950-1979. Spine (Phila Pa 1976) 15:31-35

3. Singhal A, Mitra A, Cochrane D, Steinbok P (2013) Ring apophysis fracture in pediatric lumbar disc herniation: a common entity. Pediatr Neurosurg 49:16-20
4. Kurth AA, Rau S, Wang C, Schmitt E (1996) Treatment of lumbar disc herniation in the second decade of life. Eur Spine J 5:220-224

5. Dang L, Liu Z (2010) A review of current treatment for lumbar disc herniation in children and adolescents. Eur Spine J 19:205-214

6. Slotkin JR, Mislow JM, Day AL, Proctor MR (2007) Pediatric disk disease. Neurosurg Clin N Am 18:659-667

7. Gadjradj PS, Harhangi BS, Amelink J, van Susante J, Kamper S, van Tulder M, Peul WC, Vleggeert-Lankamp C, Rubinstein SM (2020) Percutaneous transforaminal endoscopic discectomy versus open microdiscectomy for lumbar disc herniation: a systematic review and meta-analysis. Spine (Phila Pa 1976), Publish Ahead of Print

8. Gadjradj PS, Harhangi BS (2016) Percutaneous transforaminal endoscopic discectomy for lumbar disk herniation. Clin Spine Surg 29:368-371

9. Chen Y, Song R, Huang W, Chang Z (2018) Percutaneous endoscopic discectomy in adolescent lumbar disc herniation: a 3- to 5year study. J Neurosurg Pediatr 23:251-258

10. Lee DY, Ahn Y, Lee SH (2006) Percutaneous endoscopic lumbar discectomy for adolescent lumbar disc herniation: surgical outcomes in 46 consecutive patients. Mt Sinai J Med 73:864-870

11. Mayer HM, Mellerowicz H, Dihlmann SW (1996) Endoscopic discectomy in pediatric and juvenile lumbar disc herniations. $\mathrm{J}$ Pediatr Orthop B 5:39-43

12. Wang X, Zeng J, Nie H, Chen G, Li Z, Jiang H, Kong Q, Song Y, Liu H (2014) Percutaneous endoscopic interlaminar discectomy for pediatric lumbar disc herniation. Childs Nerv Syst 30:897-902

13. Zheng C, Wu F, Cai L (2016) Transforaminal percutaneous endoscopic discectomy in the treatment of far-lateral lumbar disc herniations in children. Int Orthop 40:1099-1102

14. Seiger A, Gadjradj PS, Harhangi BS, van Susante JL, Peul WC, van Tulder MW, de Boer MR, Rubinstein SM (2017) PTED study: design of a non-inferiority, randomised controlled trial to compare the effectiveness and cost-effectiveness of percutaneous transforaminal endoscopic discectomy (PTED) versus open microdiscectomy for patients with a symptomatic lumbar disc herniation. BMJ Open 7:e018230

15. Group R (2019) Automated percutaneous and percutaneous endoscopic discectomy. http://blue.regence.com/trgmedpol/surgery/ sur145.pdf. Accessed Date Accessed 2019 Accessed

Publisher's note Springer Nature remains neutral with regard to jurisdictional claims in published maps and institutional affiliations. 